\title{
A dificuldade em definir cidade: atualidade da discussão à luz de contributos recentes
}

\author{
The difficulty in defining city: current discussions \\ enlightened by some recent contributions
}

Manuel Pereira Soares [l]

\begin{abstract}
Resumo
Neste artigo, pretende-se abordar a questão da definição de cidade. Começa por se recorrer a alguns dos contributos teóricos que, ao longo dos anos, foram sendo dados para essa discussão, convocando alguns dos sociólogos que se debruçaram sobre o tema. Tentaremos, de seguida, perceber como é definida a cidade de acordo com as suas diferentes realidades. Critérios como os da dimensão e densidade parecem estar presentes em todas as tentativas de definição, mas não são suficientes para conseguir consenso para uma definição única, que parece não ser possível encontrar. A funcionalidade toma importância como complemento para essa discussão. Debruçamo-nos igualmente sobre a realidade portuguesa e a dicotomia cidade/vila tão presente no contexto nacional.

Palavras-chave: definição de cidade; cidade; vila; Portugal urbano; funcionalidade.
\end{abstract}

\begin{abstract}
This article intends to approach the question of the definition of city. It begins by recalling some of the theoretical contributions that have been given to this discussion over the years, summoning some of the sociologists who have focused on this issue. Then it tries to understand how city is defined according to different realities. Criteria such as dimension and density seem to be present in all the definition attempts, but they are not sufficient to produce a single consensual definition, which appears to be impossible to find. Functionality has become important as a complement to this discussion. We also report on the Portuguese reality and explore the city/town dichotomy, so present in the national context.
\end{abstract}

Keywords: definition of city; city; town; urban Portugal, functionality. 


\section{Introdução}

Vivemos num mundo que se urbaniza a cada dia. Mais de metade da população mundial habita em cidades. Contudo, a cidade não é igual em toda parte. Não falamos do mesmo quando o que está em análise é uma cidade de Portugal ou do Brasil, por exemplo, e o facto de não existir uma definição única e consensual parece comprovar essa afirmação. Experimente-se pedir a alguém que nos dê uma definição de cidade e provavelmente teremos de lidar com alguns silêncios e outras tantas hesitações até que, finalmente, a resposta surgirá assente na dimensão e densidade. Esta é a imagem clássica das grandes aglomerações urbanas que vamos retendo: milhares e milhares de pessoas formigando em ruas infindáveis no meio de prédios altos. Mas como explicar que existam cidades com poucos habitantes e apenas meia dúzia de casas e aglomerados com milhares de pessoas e de prédios que não o são?

A cidade é um assunto complexo. Defini-la torna-se, portanto, tarefa árdua e de difícil, se não mesmo impossível, unanimidade.

Desde o fim das muralhas da cidade medieval que a noção dos limites da cidade deixou de existir. Retirem-se as placas toponímicas dos lugares, e podemos hoje percorrer um país de lés-a-lés sem sabermos ao certo onde estamos, se já saímos de determinada cidade ou se entrámos já numa outra. A cidade vai-se espraiando em seu redor e absorvendo os territórios adjacentes ou dando origem a novos territórios.

Procurar definir a cidade apenas com base na sua densidade ou dimensão é redutor, como veremos neste texto. Há que lhe acrescentar outros critérios, como o da funcionalidade, por exemplo. Só assim conseguiremos uma imagem mais clara do que poderá (ou não) ser uma cidade. É essa a proposta para os parágrafos seguintes, nos quais nos deteremos de forma especial na realidade portuguesa, já de si tão diferente de exemplos de outros países da Europa.

Nesse sentido, recorrendo a uma revisão bibliográfica de alguns textos seminais dos estudos urbanos e pondo-a em diálogo com notícias e problemáticas levantadas pelos indicadores estatísticos utilizados por diversas entidades, procuraremos atualizar a discussão em torno da definição do que é, afinal, uma cidade.

Começaremos este texto por apresentar um resumo de alguns contributos teóricos para a problemática relativa à definição de cidade, abordando, de seguida, alguns dos modelos de construção de cidade surgidos ao longo do tempo. Depois desse exercício teórico, haverá lugar para procurar dar uma resposta à questão do que é, afinal, uma cidade. Tentaremos, na sequência, perceber como é a cidade em Portugal e quais as funções que a cidade compreende. Por último, haverá, ainda, lugar para abordar os critérios estatísticos que vão norteando esta discussão de definição do que é uma cidade, especialmente em Portugal e na Europa.

\section{Alguns contributos teóricos para a problemática da definição de cidade}

A cidade existe há séculos, mas foi principalmente a partir da cidade industrial que se começou a produzir teoria urbana (Parker, 2004, pp. 8-26). 
Desde sempre, os sociólogos bifurcaram o entendimento do sentido do que se entende por urbanização em dois: a "concentração espacial de população com base em certos limites e densidade", por um lado, e "a difusão de um sistema de valores, atitudes e comportamento chamado cultura urbana", por outro (Castells, 1977, p. 9). Desse modo, a forma espacial aliada ao tal sistema de valores e comportamentos seria um modo de identificar a urbanização. Castells não partilha dessa ideia e, embora reconheça que a ligação entre forma e cultura urbana possa servir de hipótese, considera que ela não constitui um elemento definidor de urbanização (ibid., p. 10). Castells recorre à Gordon Child, para explicar que, em termos históricos, a cidade era o lugar onde se concentravam os especialistas não produtivos, como era o caso dos padres e dos funcionários, por exemplo (ibid., p. 11).

Max Weber defendia que as cidades replicavam características que já se encontravam nas cidades do norte da Europa no século XVI (Parker, 2004). Para Weber, "economicamente definida a cidade é um assentamento de habitantes que vive essencialmente do comércio, mais do que da agricultura" (Weber, 1969, p. 23; tradução nossa). A natureza da cidade está, portanto, muito associada ao mercado. Mas não é todo e qualquer mercado que torna um lugar em cidade, apenas "naqueles casos em que os habitantes conseguem satisfazer uma parte substancial das suas necessidades económicas no mercado local", e maioritariamente com os produtos provenientes dos arredores, isso sucede (ibid., p. 24; tradução nossa). Ainda assim, o que confere, no entender desse autor, um carácter especial à cidade é, precisamente, a existência do comércio e as atividades com ele relacionadas, sejam os comerciantes, artesãos especializados, funcionários, etc. (Parker, 2004), pelo que a cidade se apresenta como um espaço privilegiado para comércio, um grande mercado.

Nalguns dos textos seminais da sociologia urbana, foram sendo apresentados aqueles que poderiam ser os elementos definidores do que seria a cidade. Louis Wirth, por exemplo, refere-nos a dimensão, a densidade e a heterogeneidade como aspetos fundamentais de uma cidade (Wirth, 2001). As observações de estudiosos como Wirth eram feitas com base na explosão urbana que as cidades industriais de início do século XX iam observando, momento em que o urbanismo como modo de vida, na expressão desse autor, ia se afirmando mais do que nunca. Georg Simmel, no texto $A$ metrópole e a vida do espírito, encontra no individualismo permitido pela cidade uma marca distintiva que traça uma fronteira entre a cidade e o campo (Simmel, 2001). A "individualidade metropolitana é a intensificação da vida emocional decorrente da mudança brusca e continuada dos estímulos internos e externos", afirmava Simmel (ibid., p. 31). Do exacerbar de estímulos aos quais o indivíduo está sujeito na cidade decorre a "atitude blasé" de que nos fala esse autor e que permite, ao indivíduo, contornar de forma racional as perturbações com que é ameaçado pelas "flutuações e descontinuidades do ambiente externo", em vez de o fazer de forma emocional como sucedia na vida da aldeia (ibid., p. 32). Não é que Simmel ignore os defeitos da cidade, mas ele enaltece as vantagens da libertação do paroquialismo e da vigilância da Gemeinschaft decorrente da pequena aglomeração (Parker, 2004, p. 14). Também Walter Benjamin, nesse caso utilizando a figura 
do flâneur, procurará abordar essa questão que se prende com o individual no meio da multidão, à resistência aos estímulos da grande cidade, ao estilo de vida resultante das grandes cidades (Franklin, 2001).

Ebenezer Howard, em inícios do século $X X$, identifica algumas limitações à vida nas cidades, às quais faltam, em seu entender, as amenidades do campo. A vida no campo, por sua vez, também carece dos atrativos da vida na cidade pelo que seria importante existir uma terceira solução "na qual todas as vantagens da vida mais ativa na cidade e toda a beleza e as delícias do campo podem estar combinadas de um modo perfeito" (Choay, 2013). Na sequência dessa necessidade, surge a ideia das cidades-jardim, uma terceira via que juntava campo e cidade, modelo predefinido de cidade que poderia ser replicado por todo o lado, sempre com o mesmo princípio em vista: mesclar os dois modelos de vida até aí conhecidos, sem que as desvantagens de um e de outro se fizessem sentir (Howard, 1902). Nesse sentido, procurava delinear-se um modelo predefinido em que as cidades eram quase como que desenhadas a la carte, juntando as amenidades do campo às vantagens da cidade num só espaço. Lewis Mumford também reconhecia importância ao espaço natural, mas entendia como errado transportar a cidade para o campo, destruindo espaço natural em favor do cimento (Choay, 2013). Para ele, a cidade devia ser desdensificada, devendo os espaços degradados das cidades antigas serem substituídos por parques e jardins que transformassem as cidades em espaços tão agradáveis quanto os primeiros subúrbios tinham sido, sem necessidade de se ter de se sair da cidade para tal (ibid.). Mumford, contudo, antevia que as novas cidades seriam afetadas pela economia, que obrigava a arquitetura a recorrer a novos materiais, mais baratos e fáceis de produzir, que vinham sendo produzidos e que determinariam que os novos edifícios se tornassem cada vez mais parecidos e mais afastados da graciosidade das construções dos séculos precedentes, e isso também ditaria as novas formas das cidades, além de impactar na forma como as pessoas e as cidades se iriam relacionar (Mumford, 1970, pp. 402-498). Já Jane Jacobs, por sua vez, advoga as cidades em grande escala. As cidades-jardim de Howard estavam datadas e referiam-se a uma época que tinha precedido uma série de progressos surgidos em diversos campos que haviam transformado "revolucionariamente condições perigosas e degradantes que, por algum tempo, foram características inevitáveis da vida dentro das grandes cidades (Choay, 2013, p. 300). Para Jacobs (1961), a cidade devia ter uma vida intensa, um pulsar constante que ocupasse as 24 horas do dia. Uma cidade com muita atividade permitiria, no entender dessa autora, uma segurança maior, pois haveria constantemente a presença dos olhos dos que eram os proprietários naturais da rua para a vigiar, e seriam eles que, ao usarem com agrado a rua, acabariam inconscientemente por policiá-la (ibid., pp. 35-36). Ao mesmo tempo, a confiança nas ruas da cidade resultaria de inúmeros contactos entre as pessoas ao longo do tempo (ibid., p. 56). Os problemas da cidade resolviam-se vivendo mais a cidade e não compartimentando o espaço urbano em zonas diferentes, o que provocaria que certos locais se apresentassem desertos durante períodos consideráveis do dia e da noite (ibid., pp. 168-169). 


\section{Modelos de construção de cidade}

A cidade industrial sofre mutações violentas e repentinas. 0 seu crescimento quase sem limite é acompanhado de um êxodo dos campos para a cidade. Estas veem surgir novas funções urbanas, e surge a necessidade de se adaptarem à sociedade que nelas habita, fruto das críticas que vão surgindo (Choay, 2013). É nessa sequência que nos deparamos com a necessidade do surgimento de modelo(s) de construção de cidade. Choay apresenta três modelos: o progressista, o culturalista e o naturalista. Referimo-nos ao urbanismo que será executado por especialistas, normalmente arquitetos, e este ponto estabelece uma diferença com aquilo que a mesma autora afirmava ser o preurbanismo, "obra de generalistas (historiadores, economistas ou políticos)" (ibid., p. 18). 0 modelo progressista estará associado à modernidade. As necessidades humanas são identificadas no quadro de quatro funções: habitar, trabalhar, locomover-se e cultivar o corpo e o espírito (ibid.). 0 planeador passa, fruto dos avanços da técnica, a poder fazer a cidade em qualquer local, independentemente das suas especificidades físicas. Importam, à cidade progressista, a eficácia e a estética, apenas isso (ibid., p. 21). Existe a preocupação com a saúde e o higienismo, que se traduz em unidades de habitação autónomas, separadas umas das outras por espaços verdes. A cidade industrializada passa a ser um "instrumento de trabalho" e, assim sendo, para que ela possa cumprir essa "função de instrumentalidade", as suas diversas funções devem ocupar áreas diferentes, o que se materializa no zoneamento (ibid., p. 22).

Choay apresenta-nos, também, o modelo culturalista, que começa por se opor ao progressista na questão dos limites: para esse modelo, os limites, quer físicos quer populacionais, devem existir. A obsessão dos seus autores pela questão dos limites, que devem estar presentes desde a rua até à cintura verde que delimita a cidade, originará críticas ao modelo, que o reduz a uma tentativa de voltar à cidade medieval, acusando os seus teóricos de nostálgicos (Choay, 2013, p. 28). Sitte, Howard e Unwin, fundadores desse modelo, demonstram preocupação com o espaço verde, que deve estar presente na cidade de forma marcada; advogam um equilíbrio da população em termos de classes etárias e nos sectores do trabalho; pretendem "particularidade e variedade ao espaço interior da cidade"; e defendem uma "ordem espacial modelo" para essas cidades (ibid., p. 27).

0 último dos modelos, o naturalista, resulta em grande medida da corrente antiurbana americana do século XX (ibid., p. 29). Materializado na Broadcare City, de Frank Lloyd Wright, esse modelo pretende fazer uma junção dos dois modelos anteriores, colocando o enfoque nas unidades habitacionais de carácter individual em comunhão com a natureza, mas interligado com os restantes centros funcionais dispersos pela cidade, através dos meios disponibilizados pela técnica, esquecendo os limites impostos pelo modelo culturalista. Esse modelo tem a particularidade de se apresentar simultaneamente aberto e fechado, indo buscar características dos outros dois modelos, tornando-o complexo, no dizer de Choay. 
A história urbana recente permite-nos concluir que todos esses modelos tiveram seguidores e foram sendo aplicados em maior ou menor escala em nível mundial. Contudo, nenhum teve força para se impor e se tornar modelo único e consensual.

\section{0 que é afinal uma cidade?}

Embora pareça óbvio o que é a cidade (Salgueiro, 1992, p. 26), defini-la não é fácil, e têm sido vários os autores que têm tentado fazê-lo sem que o consenso numa explicação única e inequívoca surja. É, contudo, muito provável que alguém a quem seja pedido para dar uma definição de cidade aborde um, dois ou mesmo os três aspetos utilizados por Wirth (2001), e elementos, como a dimensão e a densidade, terão grande probabilidade de serem aludidos. Nesse sentido, podemos entender que uma cidade será, por natureza, um espaço altamente densificado e de grande dimensão, "uma aglomeração de gente, de capitais e de outras forças de produção num espaço limitado, mas também uma forma de povoamento, um lugar na paisagem dotado de características peculiares em termos de forma e de imagem" (Salgueiro, 2005, p. 176). As típicas imagens das grandes cidades americanas, asiáticas, sul-americanas e mesmo europeias conduzem-nos a essa ideia: extensões intermináveis de prédios com milhares ou mesmo milhões de pessoas percorrendo as suas longas ruas e avenidas.

Mas, se a definição assenta em questões como dimensão e densidade, como explicar que existam cidades com poucos milhares de habitantes e vilas com largas dezenas de milhar? A questão da densidade não parece, portanto, ser elemento suficiente para se saber o que é ou não cidade. E essa dificuldade conduz ao problema com que se debatem há anos os estudiosos. Não há critérios uniformes que permitam, independentemente do contexto, definir com clareza o que é uma cidade, ou meIhor, não existe uma definição única de cidade. Daí que se possa concluir que a cidade se apresenta como uma qualificação das povoações sem grande efeito em termos práticos (Salgueiro, 1992, p. 25).

Além desse aspeto, pode-se também destacar o chamado "paradoxo urbano", que se traduz no facto de, por um lado, e num mundo mais urbanizado, as cidades serem cada vez mais iguais, os seus traços serem encontrados em toda a parte; e, por outro lado, elas serem estudadas e vistas como lugares peculiares, como lugares particulares com papéis específicos (Balducci e Fedeli, 2008).

A literatura produzida tem procurado fornecer algumas pistas para tentar encontrar um corpus de informação que permita chegar a uma definição, que acabam por se revelar normalmente divergentes, dependendo do autor do qual falamos ou da disciplina da qual ele é oriundo. Como nos diz Salgueiro (2005, p. 176), cidade será o local onde encontramos maior variedade de equipamentos, como universidade, hospital, museus, bibliotecas, atividades produtivas não agrícolas e equipamentos de transporte, por exemplo. Para Rémy e Voyé (2004) a cidade surge "logo que se passe de uma situação de autoprodução de vários bens socialmente valorizados a um estádio em que a produção desses bens é considerada, tendo de passar por lugares e por atores especializados" (ibid., p. 34). A questão aqui assenta, portanto, na oposição do campo (que produz os bens) 
à cidade (que os transforma), um pouco na linha da cidade parasitária de Hoselitz à qual esses autores aludem: a cidade que nada produz e apenas aproveita o que o campo lhe fornece (ibid., p. 39). Contudo, e ainda pelos mesmos autores, a oposição cidade/campo não deve ser vista apenas do ponto de vista da densidade, dimensão e heterogeneidade, mas deve-se, sim, colocar o enfoque na questão da funcionalidade e do poder que a cidade concentra. E mesmo a questão da produção, elemento caracterizador do campo durante todo o tempo em que à cidade coube a quase exclusividade da transformação das matérias, se válida durante séculos, assistiu a uma mudança de paradigma com a revolução industrial, que transformou as cidades igualmente em centros de produção.

Goitia (2008) alerta para o facto de se incorrer no erro de querer encontrar-se uma definição única de cidade, e ela não é possível, pois diferirá sempre, porquanto se refere a cidades diferentes, desde a clássica em oposição à medieval, passando pela europeia, construída em cima de um substrato de séculos, até à americana. Assim sendo, Goitia lembra Oswald Sprengler quando este afirma que a cidade não se define pela sua dimensão, mas sim pela "alma da cidade", a alma que falta às cidades modernas americanas, da Ásia e da Europa industrial, pois estas não têm essa "essência denominada cidade", são centros onde não "se vive uma vida peculiar e própria" (ibid., pp. 17-18). Por essa razão, Goitia fala-nos do problema das cidades sem alma que ele encontra ao ver certas aglomerações norte-americanas às quais resiste a chamar cidade, não obstante o seu volume e população consideráveis, entendendo que as cidades sem alma são frutos da cidade industrial (ibid., pp. 18-19).
Ascher (2010) entende estarmos a viver uma nova revolução urbana que vem na sequência das duas que a precederam: a cidade clássica e a cidade industrial. Começa por dar a definição de cidade apresentada na linha da de Rémy e Voyé, isto é, "como agrupamentos de populações que não produzem os seus meios de subsistência alimentar" (ibid., p. 21). Mais uma vez se alude aqui à cidade parasitária que aproveita o que o campo produz. Contudo, e já sabemos, essa foi a realidade, em certa medida, que se viveu no período pré-industrial. A cidade passou a ser muito mais do que uma aglomeração que não produzia os seus meios de subsistência (sempre foi). Com o desenvolvimento dos transportes, passou a existir a possibilidade de escolher o local de residência ou do estabelecimento das atividades. Os lugares passaram a alterar a sua natureza. 0 que outrora foi espaço agrícola pode, quando necessário, passar a ser espaço urbano, assim seja entendido que isso é útil ou necessário (ibid., p. 39). Isso sempre assim aconteceu e, historicamente, "as cidades irradiavam, muitas vezes desordenadamente, de antigos e estabilizados núcleos históricos para o espaço circundante" (Barros, 1990, p. 45). Para Ascher, entrámos já na terceira revolução urbana, aquela que, assente na tecnologia, permitiu a mudança profunda dos territórios, o aproximar das distâncias, o tornar perto o que fisicamente está distante. Essa nova revolução terá, naturalmente, impactos nas cidades e nos modos de vida urbanos e traduz-se em cinco grandes evoluções que caracterizam essa terceira revolução: a metapolização; a transformação dos sistemas urbanos de mobilidade; a formação de espaços-tempo individualizados; a redefinição das relações entre interesses individuais, coletivos e gerais; e as novas 
relações com riscos (Ascher, 2010, p. 61). Em decorrência a essa realidade, as conurbações vão crescendo e absorvendo as cidades, vilas e aldeias dos arredores, tornando cada vez mais difícil descortinar os limites físicos e sociais entre a cidade e o campo (ibid., p. 63.)

Talvez seja necessário recuar até a cidade medieval para poder, com clareza, estabelecer uma fronteira inequívoca entre o espaço urbano e o espaço rural, fronteira esta que existia em forma de muralha que envolvia a urbe e a separava (protegia mesmo) do exterior não urbano. Se havia um traço que tornava simples perceber onde acabava o campo e começava a cidade, ele traduzia-se através da muralha, que nos indicava que, dali para dentro, outro mundo se abria (Goff, 2007, p. 69). 0 camponês que se dirigia à cidade para vender os seus produtos sabia que entrava num espaço que não era o seu. A cidade era o local do comércio, onde o homem do campo levava o que tinha produzido e buscava as matérias transformadas. A cidade era um local diferente para gente diferente. Habitar na cidade tinha as suas exigências. Era necessário saber um ofício, algo que permitisse transformar 0 que vinha do campo em mercadoria útil que, depois, pudesse ser vendida, retirando daí um rendimento, fazendo de um determinado mister modo de vida (Goitia, 2008, p. 80), por isso a cidade se organizava em bairros que correspondiam ao exercício de determinada profissão ( Rémy e Voyé, 2004, p. 40). Mas a cidade acolhia muito mais do que artesãos. Era também onde se concentrava o poder, quer religioso quer político. Era onde os Senhores assentavam, vivendo dos rendimentos que o privilégio de ser proprietário Ihes conferia (Jibid., p. 38), embora esses Senhores constituíssem, ao mesmo tempo, um obstáculo à burguesia medieval que despontava, ao limitarem a sua liberdade de ação para fazerem os seus negócios, o que, consequentemente, tinha implicações no desenvolvimento da própria cidade (Goitia, 2008, pp. 80-81). Para o rural, que aí ia vender os produtos em bruto, a cidade apresentava-se como muito mais do que local de troca de produtos por outras mercadorias ou dinheiro. Era o espaço que lhe permitia, embora de forma passageira, sociabilizar com outras pessoas, ver o que não podia ver no campo, com sorte encontrar alguma diversão e as outras funções que Ihe estavam vedadas pela vida no campo. A cidade não era para todos, e por essa razão apresentava-se como objeto de desejo para quem a ela não conseguia aceder (Goff, 2007, p. 69), a não ser quando os portões (proteção às ameaças que vinham do exterior, não só militar como, em certa medida, também às ameaças à própria ideia de urbanitas por parte dos que não eram da cidade) Ihes eram abertos para permitirem uma breve passagem para poderem tratar do que os tinha levado até lá.

A evolução tecnológica, nomeadamente no que ao modo de fazer a guerra dizia respeito, fez com que as muralhas deixassem, a certa altura, de conseguir cumprir a sua função, que era proteger das ameaças do exterior, tornando-as inúteis (Lamas, 2011, p. 204). Com o seu desaparecimento físico, e à medida que elas iam sendo destruídas, abria-se a possibilidade de a cidade se expandir para fora do perímetro ao qual os muros anteriormente a circunscreviam. Pode falar-se num primeiro momento de expansão urbana, o momento em que a fronteira física que separava o urbano do rural se 
começava a desvanecer, o momento em que os limites físicos da cidade deixavam de existir. Esse fenómeno, da expansão histórica da cidade, irá desenvolver-se durante anos e terá impactos duradouros em muitas, nomeadamente nas europeias onde mais se fez sentir. A cidade concentrada, compacta, limitada e circunscrita começa a alargar, a conhecer novos espaços, novos centros até. Esse alargamento vai deixando marcas, nalguns casos poderá falar-se até em cicatrizes, que ajudam a escrever a história de cada cidade, porquanto esses vestígios que ficam, quer físicos quer toponímicos, remetem para a memória do que ali existiu antes, como se pode encontrar em muitas das atuais cidades de origem medieval. Nem sempre esse alargamento foi pacífico. Em Genebra, por exemplo, a burguesia manifestou forte oposição à destruição das muralhas, pois adivinhava que isso eliminaria os limites da cidade, conferindo à muralha mais do que um valor de proteção às agressões externas, fazendo dela como que uma marca de delimitação clara do que era a cidade e do que não era, e que parte dos habitantes da cidade não aceitava ser varrida da paisagem urbana (Rémy e Voyé, 2004, p. 71).

Definir a cidade torna-se, portanto, um desafio difícil de ultrapassar. Dir-se-ia que há tantas definições quantos definidores. 0 recurso à etimologia poderá dar algum contributo para a obtenção de um conjunto de informação que permita apontar para um caminho comum. Os termos referentes à cidade têm proveniência latina. A urbs, civitas, villa constituíram a base para os vocábulos modernos relacionados com a cidade, começando na urbe, derivada de urbs; na cidade, resultante da civitas; e na vila, proveniente da villa (Goff, 2007, pp. 10-14). Curiosamente, encontramos na evolução dessas palavras novos étimos que usualmente são utilizados para procurar estabelecer marcas caracterizadoras do modo de ser urbano. A urbanidade e o civismo são dois desses exemplos, quando pretendemos marcar fronteiras de comportamento e de saber-estar que permitam estabelecer diferenças entre 0 viver em sociedade num contexto de aglomeração de gente heterogénea e anónima. É evidente que essas marcas são também válidas para o espaço não urbano, e isso é feito no sentido de procurar que esse espaço se possa elevar, se possa aproximar ao que sucede na cidade, exemplo maior do viver em aglomeração.

A cidade começa por ser um "sítio natural no espaço geográfico" (Lacaze, 1999, p. 16). Tradicionalmente, ela surgia junto das vias de comunicação, rios, estradas e portos que permitiam o fluxo das mercadorias. Era igualmente importante que o espaço envolvente fosse rico em terra fértil e recursos naturais que permitissem abastecê-la com os produtos essenciais para a sobrevivência dos seus habitantes. É só mais tarde na história que surgem as cidades de "criação voluntária" (ibid., p. 17). Estas, ao contrário das anteriormente descritas, surgem como fruto de necessidades ou de estratégias que se iam fazendo sentir. Madrid, por exemplo, está estrategicamente colocada no centro de Espanha, parecendo quase querer desempenhar uma função panóptica de observação do reino; poder controlar tudo em seu redor. Brasília, por sua vez, procurou descentralizar 0 poder, levando-o para uma zona quase desabitada do País, procurando equilibrar o jogo de forças das cidades, surgindo como contraponto ao poder de cidades como São Paulo ou o Rio de Janeiro. Esta foi uma outra forma de se fazer a urbanização, não a espontânea que originou 
a grande maioria das cidades, mas a utilitária, que foi criando as cidades novas, muitas delas resultantes das explosões demográficas da história (ibid.).

Na Europa, as cidades vivem na atualidade um momento em que, em termos demográficos, parecem crescer e estagnar ao mesmo tempo, contrariamente ao que sucede noutros continentes em que a dinâmica de crescimento parece imparável (Balducci e Fedeli, 2008, p. 243). Esse fenómeno parece dever-se aos diferentes ciclos económicos que os diversos países vão vivendo, fazendo com que, nuns casos, alguns territórios, por se encontrarem em fase de mudança, observem momentos de crescimento, enquanto outros, por já terem passado por essa fase, atravessem momentos de estagnação. As cidades maiores assistem, ainda assim, a crescimentos mais notórios que os territórios de menor dimensão (ibid.).

A mobilidade desempenha também um papel fundamental no redesenhar das áreas urbanas. É ela que, associada aos preços sempre crescentes da habitação, faz com que os centros sejam cada vez mais desprovidos de residentes e que as cidades se espraiem para as periferias, especialmente quando se trata de famílias jovens com crianças (ibid., p. 245).

Embora os processos de urbanização se generalizem praticamente em todo o globo, as dinâmicas que lhes estão associadas divergem de país para país ou de continente para continente, originando resultados diferentes. Enquanto na Europa assistimos à suburbanização cada vez mais crescente, justificada por razões económicas e não por uma vontade intrínseca do indivíduo de fugir do centro; nos EUA essa mesma suburbanização deve-se muitas vezes a tentativas de encontrar mais espaço a melhor preço, abandonando intencionalmente o centro, que fica reservado para o trabalho (Forsyth, 2012). No caso asiático, o imparável êxodo rural para as cidades, ao qual assistimos na atualidade e que, durante anos, políticas governamentais impediram, nomeadamente na China, através de mecanismos como o hukou, ${ }^{1}$ faz com que as cidades do período pré-êxodo não tenham qualquer possibilidade de acolher os milhões de novos residentes que a elas se dirigem, originando o surgimento de centenas de novas cidades criadas de raiz para albergar esses milhões de novos urbanos. Estes são apenas três exemplos que espelham três realidades diferentes de processos de urbanização, reforçando, mais uma vez, a dificuldade que existe em encontrar uma definição única de cidade.

\section{A cidade em Portugal}

Em Portugal as cidades foram-se estabelecendo ao longo das vias de comunicação fluviais e dos portos marítimos, dispersando, depois, pelo território por motivos demográficos ou militares. Historicamente, o título de cidade ou promoção de vila a esse estatuto era de responsabilidade político-administrativa concedida pelo Rei ou Parlamento, estando essa responsabilidade na atualidade reservada à Assembleia da República e às Assembleias Regionais dos Açores e da Madeira (Salgueiro, 1992, p. 19). A lei que regula a determinação e categoria das povoações em Portugal é a lei n. 11/1982 de 2 de junho e assenta numa junção de critérios demográficos com funcionais. Desde o século XIX, a rede urbana pouco se alterou, desenvolvendo-se a partir dos aglomerados urbanos historicamente existentes, que se foram adaptando à evolução 
demográfica (Costa, 1993). Muitas das cidades criadas em Portugal eram-no no sentido de tentar valorizar determinadas regiões pouco povoadas ou com fins estratégicos, como sucedeu com os casos da Guarda e de Vila Real, que foram criadas para repovoar territórios devastados por guerras e com o intuito de servirem de guarda à fronteira com Espanha (Salgueiro, 2005, pp. 180-181). Não existiu em Portugal o hábito de criar cidades de raiz, apenas as cidades de Fátima (origem religiosa), Entroncamento (tal como indica o nome, por ser local de cruzamento de várias linhas ferroviárias) e Santo André (para servir de assentamento da população que se esperava que o projeto de Sines viesse a atrair) surgiram na linha das cidades novas (Costa, 1993, pp. 6-7). De resto, as cidades portuguesas devem a sua origem à evolução dos aglomerados que já existiam. A dicotomia cidade/campo não tem de corresponder obrigatoriamente à dicotomia rural/ urbano, pois podemos encontrar cidades "dominantemente rurais e campos marcadamente urbanos" (Baptista, 2006, p. 58). Historicamente, Portugal é caracterizado como sendo um país de vilas e aldeias, e podemos encontrar a realidade atrás descrita manifestada através de cidades rurais e campos urbanos (Carvalheiro, 2008, p. 48). A década de 1980 foi aquela em que se assistiu à maior promoção de vilas a cidades em Portugal, especialmente entre 1984 e 1986, em que 34 vilas passaram a ostentar o estatuto de cidade (Salgueiro, 1992, p. 24).

0 caso português tem assistido a uma assinalável litoralização da população, que se vai concentrando no eixo que começa acima do Porto e vai até sul de Lisboa, formando uma aglomeração urbana ininterrupta em que se torna difícil saber onde acaba uma cidade e começa outra, algo que se pode assemelhar, salvo o exagero, à ideia de cidade linear que o urbanista espanhol Arturo Soria y Mata idealizou em finais do século XIX. Assiste-se também a uma assinalável concentração populacional na zona do litoral algarvio, em contraponto com a chamada desertificação do interior, cuja mancha livre do território é pontualmente interrompida por alguns aglomerados mais significativos, normalmente referentes às capitais de distrito e a seu entorno muito próximo.

Embora muito marcada pelas áreas Metropolitanas de Lisboa e do Porto (AML e AMP), que concentram cerca de $43 \%$ da população residente no país (INE, 2014), observa-se uma rede de cidades médias que vão constituindo algumas conurbações de diferentes tipologias, como, por exemplo, a de Aveiro, no centro norte do país, que, embora em dependência relativamente à Área Metropolitana do Porto (AMP), constitui uma constelação industrial com os concelhos vizinhos; e um pouco mais abaixo, Coimbra, que preside a uma constelação urbana de emprego assente nos serviços públicos proporcionados pela universidade e pelos hospitais, formada com os concelhos de Montemor-o-Velho, Soure, Miranda do Corvo, Lousã, Poiares e também Condeixa-a-Nova (Marques, 2006). Essas constelações, embora de menor dimensão que as áreas metropolitanas, acabam por também se caracterizar por terem um polo dinamizador que atrai e influencia significativa população em seu redor que faz uso da mobilidade, muito associada ao transporte individual, para se poder deslocar de casa para o trabalho ou para o local de estudo.

Não deixa de ser quase paradoxal que a cidade, enquanto termo isolado, seja tão difícil de definir e exista, depois, uma panóplia de 
expressões cujo significado é facilmente explicável através da decomposição das palavras que a compõem, como sucede com a cidade-região, cidade média, cidade-dormitório, megacidade ou cidade global, por exemplo. Nessas expressões compostas, a cidade é como que adjetivada, permitindo-nos, mesmo sem conseguirmos definir muito bem o que é uma cidade, saber de que cidade se trata quando falamos, por exemplo, em cidade-dormitório.

No grupo dessas (diríamos) cidades adjetivadas, encontramos as cidades médias, conceito que parece surgir pela primeira vez em França nos anos 1970 como alternativa às grandes cidades (Costa, 2002). No caso desse tipo de cidades, a sua definição assenta em dois aspetos: a sua dimensão à escala urbana (sempre a dimensão) e as funções e papel que desempenham no sistema urbano ao qual pertencem (ibid.). Diz ainda essa autora que, numa tentativa para se encontrar um critério mensurável que permitisse identificar uma cidade média, o congresso Ibero-Americano de Pamplona de 1996 apontou o intervalo entre 20.000 e 50.000 habitantes para se poder atribuir tal classificação. Esse número foi posteriormente revisto para outro mais baixo. $\mathrm{A}$ Comissão Europeia (CE), por sua vez, indicava que seriam cidades grandes as que tivessem mais de 250.000 habitantes, médias as que tivessem entre 100.000 e 250.000 habitantes e pequenas as que tivessem menos de 100.000 habitantes (ibid.). À luz desses critérios, Portugal teria apenas seis cidades médias no continente (maioritariamente nas AML e AMP) e uma na região autónoma da Madeira (INE, 2014). Sendo Portugal um país com pouca população, a definição de cidades médias com base no número de habitantes ${ }^{2}$ terá de ser necessariamente diferente para países como a França ou Alemanha e em comparação com outros com menor número de habitantes. Por essa razão, e como nos lembra Teresa Salgueiro, por volta do último quartel do século passado, o Instituto Nacional de Estatística e a Direção Geral de Ordenação do Território e do Desenvolvimento Urbano, através de um grupo de trabalho, geraram as tipologias de áreas urbanas em Portugal (Salgueiro, 2005, p. 185). Desse trabalho, resultou a criação de três áreas de diferente tipologia urbana: área predominantemente urbana (APU), área medianamente urbana (AMU) e área predominantemente rural (APR), visando, com base nessa informação, destrinçar territórios urbanos de territórios rurais (ibid.). A necessidade de criar nomenclatura uniforme tem gerado documentos que norteiam a análise dessas realidades, como é o caso do glossário do desenvolvimento territorial saído da conferência europeia dos ministros responsáveis por essa temática (Cemat, 2011).

Para que se possa fazer um trabalho de análise mensurável em critérios definidos, 0 INE criou, em 2002, a ideia de cidade estatística que representa uma

unidade territorial que corresponde ao ajustamento do perímetro urbano, consagrado nos instrumentos jurídicos de ocupação de solos para a povoação com categoria de cidade, ao perímetro das subsecções estatísticas utilizadas pelo INE na Base Geográfica de Referenciação da Informação (BGRI) e que a integram. ${ }^{3}$

Portugal é composto maioritariamente por cidades com baixa demografia que se podem incluir naquilo que internacionalmente se 
pretende classificar como cidade média, isto é, cuja "importância regional" e "contributo para a organização dos sistemas urbanos regionais" são determinantes (Costa, 2002, p. 108), ou seja, cidades que assumem um papel fundamental para a fixação de população fora das duas grandes áreas metropolitanas nacionais $\mathrm{e}$ que funcionam como centros dinamizadores de todo um sistema regional. É nesse sentido que uma cidade com apenas 20.000 habitantes, ${ }^{4}$ que, à luz de critérios demográficos de algumas entidades, poderia nem tampouco acolher o estatuto de cidade (Dijkstra e Poelman, 2012; Eurostat, 2016), pode ser um centro absolutamente determinante para o funcionamento de uma região, como sucede em inúmeros casos no nosso país, especialmente em toda a mancha de território do interior do país afastado do litoral, onde as pequenas e médias cidades desempenham um papel fundamental no fornecimento de emprego e serviços aos lugares mais próximos e dão contributo importante para a fixação de população.

0 papel das cidades médias assume, portanto, uma importância maior do que aquela que, à partida, o seu nome poderia sugerir. Em primeiro lugar pelo contributo que têm para a distribuição do sistema urbano nacional, já de si bastante desequilibrado em termos da concentração de população (e não só) que encontramos nas duas áreas metropolitanas nacionais, e, também, pela importância que elas podem assumir na hierarquia das redes urbanas, permitindo alguma, ou mesmo assinalável, independência relativamente às grandes cidades, descartando a quase subserviência relativa aos grandes centros que absorvem tudo em seu redor.

\section{Funções da cidade}

A ideia de função de cidade parte da aproximação às ciências biológicas numa altura em que os conceitos e processos dessa ciência passaram a ser utilizados para compreender as sociedades humanas, pelo que ela passa a ser vista como tendo uma função tal como um qualquer órgão tem a sua função num organismo (Salgueiro, 1992, p. 123).

Jaqueline Beaujeu-Garnier afirma ser importante considerar a cidade sujeito e objeto simultaneamente, porquanto ela existe materialmente, atraindo os habitantes aos quais fornece a maior parte do que necessitam, atuando, assim, como objeto, e, ao mesmo tempo, transformando esses habitantes através do ambiente urbano, assumindo a função de sujeito que molda e se deixa moldar por quem a habita (Beaujeu-Garnier, 1983, pp. 19-22). Halbwachs chamava igualmente a atenção para esse facto, ao afirmar que "o grupo 'molda' o espaço, ao mesmo tempo que se deixa 'moldar' por ele" (Silvano, 2010, p. 19). E a questão do espaço assume um papel importante, especialmente se atentarmos no facto de ele ser um produto social, resultado dos seus membros (Lefebvre, 2011). A cidade pode exercer nos indivíduos um papel variável, dependendo do seu tamanho, dos seus equipamentos e da sua riqueza (Beaujeu-Garnier, 1983, p. 23).

Quando falamos nas funções da cidade, temos de equacionar a questão da hierarquia que norteia a rede urbana, até porque "a densidade funcional e relacional das cidades é mais importante do que a sua densidade populacional" (Domingues, 1999, p. 55). Entram aqui em 
jogo os princípios de complementaridade entre aglomerados e que são decisivos para o desenvolvimento regional (ibid.). Historicamente, a cidade procurou responder às necessidades (defesa, comércio, etc.) que justificaram o seu aparecimento em determinado lugar, o seus consequentes desenvolvimento e expansão (ibid., p. 52). Em Portugal o surgimento e desenvolvimento (ou queda) das cidades têm sido assentes em funções defensivas, associadas à defesa do território; em funções de "vida de relação" e da troca, ligadas ao comércio; à industria, associada à produção; à cultura, no caso das cidades universitárias, como é o exemplo de Coimbra; aos transportes, como o porto de Sines ilustra; ou, ainda, a motivos de peregrinação, como o caso de Santiago de Compostela enquanto exemplo máximo (Salgueiro, 1992, pp. 123-145), mas que também tem correspondência em Portugal no caso de Fátima.

A cidade tem funções identificadas e que se traduzem nas de enriquecimento (acumular riquezas) que determinam, em grande medida, o seu desenvolvimento; de responsabilidade (assegurando os serviços de administração, saúde e ensino), que podem exercer uma influência que vai além do seu território e que se expande pelos centros vizinhos, determinando o seu maior ou menor poder; e de criação e transmissão, que asseguram que, através da sua acessibilidade (rede de transportes e infraestruturas, por exemplo), a cidade consegue atrair gente e exercer o seu poder de formação, informação e transformação (Beaujeu-Garnier, 1983, pp. 60-61). Contudo, nem sempre é fácil, apenas assente em critérios de funcionalidade, delimitar espaços, determinar o que é cidade ou não. Em Portugal é frequente assistir a casos de cidades que dependem em grande parte de serviços essenciais, como a saúde ou a educação, de cidades nem sempre próximas, o que não impediu que ostentassem o título de cidade, mesmo assegurando alguns desses serviços, embora de forma insuficiente. E verifica-se também que a dependência por parte de muitos lugares das proximidades das grandes capitais regionais, como no caso de Lisboa e do Porto, impede que eles possam ser considerados cidades, embora muito populosos, uma vez que essas duas cidades polarizam a maior parte dos equipamentos e recursos (Salgueiro, 1992, p. 25).

Mas, numa escala mais pequena, interessa entender a importância funcional dos lugares, desde o mais pequeno, isolado no meio da montanha, até o grande centro urbano de Lisboa ou do Porto, pois a hierarquização que os seus habitantes fazem deles prende-se muito poucas vezes com a sua dimensão ou com a sua densidade e liga-se muito às funções que eles oferecem ou às quais permitem aceder. A cidade tem como uma das suas funções principais prestar serviços (ibid., p. 123). Essas funções associam-se, por norma, à importância dos setores secundário e terciário, tal como ficou bem expresso em 1996 na classificação dos concelhos portugueses em urbanos, semiurbanos e rurais com base em critérios demográficos e funcionais, sendo exigido, para os urbanos, lugares com mais de 10.000 habitantes e com percentagens da população ativa dos setores secundário e terciário superiores à média nacional (Salgueiro, 2005, p. 184)

Se tomarmos como exemplo uma pequena vila nos arredores de uma cidade, poderemos perceber que ela influencia os pequenos lugares que integra e é influenciada pela cidade da qual depende. Para o trabalhador rural 
do pequeno lugar, que na melhor das hipóteses tem um café que lhe permite conviver com os vizinhos ou descansar um pouco do trabalho diário, a freguesia será o que, em termos funcionais, constituirá a referência para a satisfação de algumas das suas necessidades para um regular funcionamento do seu dia a dia. É lá, na sede de freguesia (unidade administrativa mínima), que encontrará a respetiva junta de freguesia, representação do poder, onde poderá tratar de alguma burocracia; o posto médico (quando existe), para resolver os problemas de saúde; e a escola, onde poderá colocar os filhos. 0 que não encontrar na sede de freguesia já o obrigará a deslocar-se à sede do concelho, onde poderá encontrar os bancos, as finanças, os correios e o tribunal. Será aqui também que conseguirá comprar alguns produtos ou objetos aos quais não consegue aceder nos espaços que descrevemos anteriormente. Para algumas pessoas, bastará subir esses dois degraus para satisfazer quase todas as suas necessidades cotidianas. Para essas pessoas, ir à vila será como ir à cidade, uma vez que, para elas, funciona como cidade, pois a forma como a veem é semelhante à do residente mais exigente que se sente obrigado a recorrer à cidade para satisfazer as suas necessidades. Dependendo das expectativas, as funções de cidade são cumpridas em diferentes níveis para diferentes atores (Beaujeu-Garnier, 1983). Assim sendo, enquanto para alguns a vila assegura as suas necessidades do quotidiano, reservando-se as deslocações para outros concelhos maiores ou para a capital de distrito para situações excecionais; para outros ela não consegue suprir a maior parte das suas necessidades, podendo limitar-se a servir apenas de espaço monofuncional, por norma residencial, obrigando-os a procurar todas as restantes funções noutro lugar. Tal como afirmava Durkheim, o espaço é "indissociável da sociedade que o habita, e é na relação que se estabelece entre ambos que se deve procurar a explicação para os tipos de organização que manifesta" (Silvano, 2010, p. 14). Enquanto para uns a sede do concelho é percecionada como cidade, para outros é aldeia.

A Carta de Atenas, saída do Ciam $^{5}$ de 1933, definia as quatro funções básicas da vida urbana: habitar, trabalhar, circular e recrear-se (Wilheim, 1979, p. 52). Um espaço que não permita o cumprimento de todas essas funções vê colocada em questão a sua capacidade de estar alinhado com a vida urbana. No caso das cidades-dormitório, por exemplo, ao centrarem a sua existência na função do habitar, não conseguindo um equilíbrio no que respeita ao trabalhar, apenas em parte assistem ao exercício da vida urbana. Parafraseando este autor:

[...] não é possível pensar em cidade sem pensar em vida urbana [...] uma população é formada por indivíduos que, ao nível das suas atividades cotidianas, estabelecem e recriam subsistemas de vida (conjuntos de atividades de significância para a vida de cada um) [...] esta escolha de subsistemas significativos determina não só o caráter dominante de uma cidade, como também, em última análise, a sua forma física. (Ibid., p. 65)

Mas, mais do que impor critérios para aferir se determinado espaço cumpre ou não as exigências da vida urbana, importa, talvez, atentar às necessidades individuais. Da mesma forma que um residente de um pequeno lugar pode considerar não necessitar mais do que uma ou outra deslocação esporádica à sede do concelho para suprir as suas necessidades, 
um residente do centro da vila pode achar-se na obrigação de se deslocar para fora dela para encontrar resposta a parte considerável das suas exigências, remetendo a vila para apenas uma ou outra função por ele considerada de menor importância. Trata-se de uma questão individual e é a capacidade que os lugares têm para contentar o mais diverso tipo de necessidades que as tornam mais ou menos importantes para os seus habitantes. Mais do que administrativamente determinar que esse lugar é cidade e aquele é vila, importa perceber se aquele que vai passar a ser cidade é autónomo na satisfação das necessidades da sua população ou se obriga a deslocações recorrentes ao concelho vizinho (que até pode ser uma vila) para as satisfazer.

Como parece ser comum com quase todos os aspetos que envolvem as questões urbanas, a distinção entre o que é vila e o que é cidade não é clara. Enquanto uns almejam alcançar o estatuto de cidade, outros nem querem pensar em deixar de ser vila. Num artigo sobre esse assunto em 2010, o Presidente de Câmara de um dos maiores concelhos portugueses pronunciava-se desta forma relativamente a este assunto:

Em oposição a vila, a (des)promoção a cidade dá a imagem de aglomerado densamente urbanizado, satélite e dormitório da capital, com características bem distintas da vila de Cascais e que queremos continuar a manter [...] [A elevação a cidade] Não adianta nada e só dá despesa com a alteração da simbologia a que obriga. (Público, 2010)

Observe-se a forma como o responsável máximo do município se refere à possibilidade de sua vila ascender à condição de cidade: essa possibilidade é vista como uma (des)promoção. Mais uma vez, mais do que a questão do termo, parece importar refletir sobre a questão das funcionalidades e da satisfação das necessidades dos habitantes. Enquanto para uns, passar de vila a cidade traz um acréscimo de estatuto e faz subir na hierarquia urbana, para outros traz apenas despesa e não acrescenta nada ao que já têm.

Ainda no mesmo artigo deparamo-nos com outra observação:

Gostaria de poder pensar a cidade de Algueirão-Mem Martins [assume Manuel do Cabo, presidente da junta desta freguesia do concelho de Sintra] mas não existe uma cidade sem pavilhão gimnodesportivo, um complexo polidesportivo, um centro de saúde que não seja num prédio de habitação com seis andares (onde as pessoas com deficiência são atendidas à porta), sem um centro dia ou um lar público, sem piscinas (há uma para 120.000 habitantes), sem creches públicas, sem um parque ou jardim digno desse nome [...]. Nada disso existe na minha freguesia. Os construtores não deixaram espaços disponíveis para outra coisa que não fosse habitação. E a culpa é da câmara municipal, que autorizou que se construísse mesmo por cima das ribeiras [...]. (Ibid., 2010)

A observação aqui feita pelo presidente à data da entrevista da junta de freguesia de Algueirão-Mem Martins é ilustrativa do que temos vindo a destacar: de pouco vale a elevação administrativa à cidade se, em termos funcionais, estamos a falar de locais que, exceção feita à sua densidade, dimensão (e até heterogeneidade), pouco diferem de lugares desprovidos das mais básicas infraestruturas. E essa é a realidade que ajuda a mascarar cidades que, elevadas a esse estatuto, na prática 
servem apenas de dormitório da cidade central da sua proximidade e onde a sua população busca a satisfação das mais elementares condições para uma boa qualidade de vida, para uma vivência plena da urbanitas que ali não conseguem encontrar.

\section{Critérios estatísticos para a definiç̧ão de cidade}

Mas é, quando se decide comparar as cidades entre países que a dificuldade em definir cidade surge de forma mais clara. Até há poucos anos, não havia, no seio da Organização para o Desenvolvimento e Cooperação Económica $(O C D E)$, uma harmonização no que à definição de cidade dizia respeito, o que provocava a inequalidade nas comparações que eram feitas no âmbito urbano entre os vários países integrantes desse organismo. Foi nesse sentido que, em 2011, a OCDE criou uma nova definição de cidade (Dijkstra e Poelman, 2012). À luz dessa nova definição, foram identificadas, na Europa, 828 cidades com um centro urbano de pelo menos 50.000 habitantes, limite mínimo para essa classificação, e metade era considerada pequena cidade. Foram também identificadas, na Europa, duas cidades globais, Paris e Londres (ibid.).

A definiç̧ão harmonizada instituída pela OCDE recorreu ao critério da densidade demográfica para encontrar uma forma uniforme de comparação entre países. A necessidade dessa harmonização surge da dificuldade em comparar cidades com base apenas na sua classificação por país. É precisamente por os critérios que determinam o que é e o que não é cidade divergirem de país para país que essa dificuldade existe. Em Inglaterra, por exemplo, é o Rei que atribui o título de cidade, classificação que fica até que ele a decida revogar. É por isso que, na atualidade, podemos encontrar locais com estatuto de cidade com apenas 2.000 habitantes, quando outros no mesmo país podem acolher mais de 3.000.000 (Dijkstra e Poelman, 2012 , p. 5). Como é fácil de entender, numa situação destas não é possível estarmos a comparar situações tão diferentes, daí a necessidade de criação de um mecanismo que permita comparar o comparável.

Essa nova definição toma como base a existência de um centro urbano identificado tendo em vista critérios de densidade demográfica. Para tal, parte-se da identificação de células densificadas com mais de 1.500 hab./ $\mathrm{km}^{2}$, células que se vão juntado a outras contíguas com o mesmo critério e que vão, em conjunto, apurar o que é o centro urbano logo que deixem de existir mais células compatíveis com o critério definido, sendo que, para isso, 0 conjunto resultante tem de totalizar pelo menos 50.000 habitantes. Num terceiro passo, procura-se verificar se, nas unidades administrativas adjacentes ao centro urbano, pelo menos metade da sua população se encontra dentro do centro urbano, concluindo-se, nesse caso, que elas são elegíveis para fazerem parte da cidade. Por fim, a cidade é definida assegurando que: 1- existe uma ligação em nível político; 2 - pelo menos $50 \%$ da população da cidade vive num centro urbano; e 3 - pelo menos $75 \%$ da população do centro urbano vive numa cidade (ibid.).

Num segundo momento, podem identificar-se as zonas de comutação baseadas nos padrões de comutação. Com base nessas zonas, 
identificam-se as de abrangência da cidade, e o mesmo centro urbano pode ser partilhado por mais do que uma cidade, estabelecendo-se, assim, diversas tipologias que vão das pequenas cidades (50.000-100.000 hab.) até às cidades extragrandes (1.000.000-5.000.000 hab.) que precedem as cidades globais que terão mais de 5.000.000 habitantes (ibid.).

Esses critérios permitirão que os centros urbanos possam, por vezes, ser maiores que os próprios limites da cidade. No seguimento dessa realidade, algumas das cidades alargadas são compostas por mais do que uma cidade.

Entende-se, portanto, que em face da necessidade de procurar alguma uniformização de critérios que permitam análises comparativas, essa metodologia tenha sido criada. Dessa forma, foram identificadas, no caso português, dezesseis cidades: doze classificadas como pequenas, uma média, uma grande, uma classificada como XL e outra como XXL (ibid.). Comparadas com as pouco mais de centena e meia de cidades que têm essa classificação legal em Portugal, observamos que essa definição da OCDE reduz largamente esse número. E há que observar que alguns dos exemplos de cidades de maior dimensão que a metodologia da OCDE identifica para a realidade nacional se referem não a cidades, mas sim a vilas. E nesse seguimento surge outra das discussões que observamos amiúde, e que se prende com a distinção entre a cidade e a vila, distinção que é possível nalguns países pelos próprios termos diferentes utilizados, mas mais difícil onde isso não acontece. No caso português, temos cidade e temos vila. No caso francês, temos cité e ville. No caso alemão, italiano ou espanhol, por exemplo, temos apenas um termo para classificar realidades diferentes (Espon, 2012, p. 3).
Uma busca em qualquer dicionário da língua portuguesa apresentará como definição primeira de vila: "Povoação, de categoria inferior à de cidade e superior à de aldeia". ${ }^{6}$ Como já foi referido anteriormente, essa definição nem sempre tem correspondência ao concreto, e esta é uma realidade não só vivida no contexto nacional, mas também em termos internacionais. Nesse sentido, o Espon (European Spatial Planning Observation Network) produziu, em 2014, um relatório no qual procurou dar algum contributo para a definição das cidades de pequena ou média dimensão (as Towns), em muitos países equivalendo às vilas portuguesas como elas são percecionadas no sentido mais comum. Para essa definição, e ao contrário da opção tomada pela OCDE para as cidades que se fundava apenas em critérios de densidade, a abordagem teve em conta critérios morfológicos, funcionais e administrativos (ibid., p. 3). Nesse sentido, essas unidades de pequena ou média dimensão têm em conta aglomerações de 5.000 a 50.000 habitantes densamente edificadas com mínimos de concentração demográfica. Ela deve igualmente ser, em termos administrativos, uma unidade de governo local e, em termos funcionais, concentrar atividades, serviços e outras funções que sirvam outro aglomerado das proximidades (ibid., p. 4). Para a identificação desse tipo de aglomerados, continua a utilizar-se células de $1 \mathrm{~km}^{2}$, embora a concentração de população aqui desça para as 300 pessoas por célula, ao contrário das 1.500 tomadas como marcador para as cidades. Verifica-se que esses territórios trabalham em estreita ligação com outros que lhes ficam nas proximidades e que, em muitos casos, acabam por cumprir os critérios definidos para a classificação de Town 
quando analisados num continuum e não de forma estanque. No caso português, verifica-se que uma parte considerável dos 308 municípios existentes são aglomerações desse tipo, fazendo do caso nacional um território que concentra grande parte da população nacional em poucas cidades e que distribui o restante por inúmeras pequenas cidades e vilas.

Por último, a organização europeia de estatística, Eurostat, e para nos mantermos em contexto europeu, define em termos estatísticos uma cidade como uma área densamente povoada, remetendo as áreas de densidade intermédias para as Towns e identificando, como áreas rurais, as de baixa densidade populacional (Eurostat, 2016). Uma cidade será, assim, uma unidade administrativa local (LAU) onde a maioria da população habita no centro urbano com um mínimo de 50.000 habitantes; a área funcional urbana será composta pela cidade e pelas suas zonas de comutação; e a região metropolitana será uma NUT $3^{7}$ estatística ou uma combinação de pelo menos 250.000 habitantes identificados como recorrendo à área funcional urbana ibid.). Esta é mais uma forma de recorrer à densidade para definir cidade, embora aqui remetendo também para a sua vertente funcional.

\section{Conclusão}

Não é fácil definir cidade. Podem existir tantas definições quantos os definidores, porquanto as realidades são distintas. Desde a cidade medieval muralhada, que a questão dos limites da cidade tornou-se quase impossível de determinar. Procura-se alicerçar os critérios de definição na densidade, dimensão e heterogeneidade, na linha de Louis Wirth, e na estafada oposição cidade/campo. Mas esses critérios não permitem, por si só, perceber por que razão determinado lugar é cidade e outro não. A funcionalidade dos espaços pode ser contributo importante para aclarar as razões que determinam o estatuto de cidades de uns espaços em detrimento de outros.

Em Portugal a realidade assenta numa concentração assinalável de grande parte da população ao redor das áreas metropolitanas de Lisboa e do Porto, onde podemos encontrar as maiores cidades. 0 restante da população distribui-se por inúmeras vilas de pequena densidade um pouco por todo o país, realidade apenas interrompida por uma ou outra aglomeração de maior dimensão e funcionalidade, normalmente coincidente com as cidades capitais de distrito.

As necessidades de comparação estatística que permitam comparar realidades semeIhantes determinaram o surgimento de definições por parte de organismos oficiais europeus e internacionais assentes em critérios de densidade. Contudo, há que lhe acrescentar a funcionalidade dos espaços, pois de outra forma continuará a ser difícil perceber por que razão determinado espaço é cidade e outro semeIhante não o é. 


\section{[I] https://orcid.org/0000-0003-3057-3283}

Universidade de Coimbra, Faculdade de Economia. Coimbra, Portugal. manpsoares73@gmail.com

\section{Notas}

(1) Nos anos 1960 do século XX, o governo central chinês tentou limitar a passagem de população rural para urbana através do hukou, sistema que fixava o local de residência de uma pessoa ao seu local de nascimento, atribuindo às pessoas duas categorias: trabalhador agrícola ou não agrícola. $O$ trabalhador não agrícola tinha acesso a regalias e privilégios aos quais o agrícola não conseguia aceder. Poder ir para a cidade era o sonho de qualquer rural (Friedmann, 2005).

(2) Os critérios de definição de espaço urbano em Portugal assentam no cumprimento de um de entre três requisitos: solo tipificado como urbano; densidade populacional com uma secção com mais de 500 hab. $/ \mathrm{km}^{2}$; lugar com população residente igual ou superior a 5.000 habitantes. Para mais informações, consultar https://www.ine.pt/xportal/xmain?xpid=INE\&xpgid=ine_cont_ inst\&INST=6251013\&xlang=pt; acesso em: 14 abr 2019.

(3) https://www.ine.pt/xportal/xmain?xpid=INE\&xpgid=ine_cont_inst\&INST=6251013\&xlang=pt, acesso em: 14 abr 2019.

(4) No caso português, bastam 8.000 habitantes para que uma vila possa ascender a cidade, embora seja exigido um conjunto de equipamentos coletivos predeterminados para que isso seja possível. Para mais informação, consultar lei n. 11/1982, de 2 de junho (https://dre.pt/ application/file/a/391896, acesso em: 14 abr 2019).

(5) Ciam era a sigla para Congresso Internacional de Arquitetura Moderna.

(6) "vila" (Dicionário Priberam da Língua Portuguesa [on-line], 2008-2013. Disponível em: https:// www.priberam.pt/dlpo/vila).

(6) As NUT são Nomenclatura das Unidades Territoriais para Fins Estatísticos.

\section{Referências}

ASHER, F. (2010). Novos princípios do urbanismo seguido de novos compromissos urbanos. Um léxico. Lisboa, Livros Horizonte.

BALDUCCI, A. e FEDELI, V. (2008). The State of European Cities Report: some critical reflections upon urban phenomena in the European Union 1. Urban Research \& Practice. v. 1, n. 3, pp. 240-253.

BAPTISTA, L. V. (2006). "Urbanização, ruralidade e suburbanidade: conceitos e realidades". In: BALSA, C. (org.). Relações sociais de espaço: homenagem a Jean Remy. Lisboa, Edições Colibri. 
BARROS, A. de (1990). A sociologia rural perante a problemática do espaço. Sociologia - Problemas e Práticas, n. 8, pp. 43-53.

BEAUJEU-GARNIER, J. (1983). Geografia urbana. Lisboa, Fundação Calouste Gulbenkian.

CARVALHEIRO, J. R. (2008). "Que margens tem o urbano? Modos de olhar e de intearagir entre a cidade e as serras". In: VAZ, D. M. (org.). Cidade e território - identidade, urbanismo e dinâmicas transfronteiriças. Lisboa, Celta.

CASTELLS, M. (1977). The urban question. Londres, Edward Arnold.

CEMAT (2011). Glossário do desenvolvimento territorial. Lisboa, Direcção-Geral do Ordenamento do Território e Desenvolvimento Urbano

CHOAY, F. (2013). O urbanismo: utopias e realidades: uma antologia. São Paulo, Perspectiva.

COSTA, E. M. da (2002). Cidades médias. Contributos para a sua definição. Finisterra, v. XXXVII n. 74, pp. 101-128.

COSTA, P. (1993). Cidades e urbanização em Portugal: uma sociologia, geografia ou economia urbanas? sOCIUS Working Papers, n. 4.

DIJKSTRA, L. e POELMAN, H. (2012). Cities in Europe the new OECD-EC definition. Regional Focus. Disponível em: http://ec.europa.eu/regional_policy/sources/docgener/focus/2012_01_city.pdf. Acesso em: 15 abr 2019.

DOMINGUES, A. (1999). Formas e escalas da urbanização difusa: interpretação e intervenção no [Nordeste] de Portugal. Inforgeo, n. 14.

ESPON (2012). TOWN Small and medium sized towns in their functional territorial context. Disponível em: https://www.espon.eu/sites/default/files/attachments/TOWN_Inception_report_ July_2012.pdf. Acesso em: 15 abr 2019.

EUROSTAT (2016). European statistics on cities - EU Law and Publications. Disponível em: https://doi. org/10.2785/626218. Acesso em: 15 abr 2019.

FORSYTH, A. (2012). Defining Suburbs. Journal of Planning Literature, v. 27, n. 3, pp. 270-281.

FRANKLIN, B. (2001). "Paris, a Capital do Século XX". In: FORTUNA, C. (org.). Cidade, cultura e globalização. Oeiras, Celta.

FRIEDMANN, J. (2005). China's Urban Transition. University of Minnesota Press.

GOFF, J. Le (2007). Por amor das cidades. Lisboa, Teorema.

GOITIA, F. C. (2008). Breve história do urbanismo. Lisboa, Editorial Presença.

HOWARD, E. (1902). Garden Cities Of To-Morrow. Swann Sonnenschein \& Co., Ltd.

INE (2014). Tipologia socioeconómica das Áreas Metropolitanas de Lisboa e Porto - 2011. Disponível em: https://www.ine.pt/ngt_server/attachfileu.jsp?look_parentBoui=219306900\&att_ display=n\&att_download=y. Acesso em: 15 abr 2019.

JACOBS, J. (1961). The death and life of great american cities. Nova York, Vintage Books.

LACAZE, J.-P. (1999). A cidade e o urbanismo. Lisboa, Instituto Piaget.

LAMAS, J. M. (2011). Morfologia urbana e desenho da cidade. Lisboa, Fundação Calouste Gulbenkian e Fundação para a Ciência e Tecnologia. 
LEFEBVRE, H. (2011). O direito à cidade. São Paulo, Centauro.

MARQUES, T. S. (2006). "Portugal urbano : mosaicos, polaridades, relacionamentos e governança = mosaicos, polaridades, relaciones e gobernanza". In: DOMINGUES, A. Cidade e democracia: 30 anos de transformação urbana em Portugal = Ciudad y democracia : 30 años de transformación urbana en Portugal. Lisboa, Argumentum.

MUMFORD, L. (1970). The Culture of Cities. Califórnia, Harcourt Brace Jovanovich Publishers.

PARKER, S. (2004). Urban theory and the urban experience. Nova York, Routledge.

PÚBLICO (2010). Cidade não, obrigado. Disponível em: https://www.publico.pt/2010/01/10/jornal/ cidade-nao-obrigado-18530849. Acesso em: 15 abr 2019.

RÈMY, J. e VOYÉ, L. (2004). A cidade: rumo a uma nova definição. Porto, Edições Afrontamento.

SALGUEIRO, T. B. (1992). A cidade em Portugal: uma geografia urbana. Lisboa, Edições Afrontamento.

(2005). "Problemas em torno de um conceito complexo". In: MEDEIROS, C. A. (org.). Geografia de Portugal - Sociedade, paisagens e cidades. Lisboa, Círculo de Leitores.

SILVANO, F. (2010). Antropologia do espaço. Lisboa, Assírio \& Alvim.

SIMMEL, G. (2001). "A metrópole e a vida do espírito". In: FORTUNA, C. (org.). Cidade, cultura e globalização. Oeiras, Celta.

WEBER, M. (1969). "The nature of the city". In: SENNET, R. (org.). Classic Essays on the Culture of Cities. Nova Jersey, Prentice-Hall, Inc.

WILHEIM, J. (1979). O substantivo e o adjetivo. São Paulo, Perspectiva.

WIRTH, L. (2001). "O urbanismo como modo de vida". In: FORTUNA, C. (org.). Cidade, cultura e globalização. Oeiras, Celta.

Texto recebido em 10/ago/2018

Texto aprovado em 28/nov/2018 